\title{
LA MÚSICA COMO ESTRATEGIA DIDÁCTICA PARA LA ENSEÑANZA DE UNA SEGUNDA LENGUA, UNA REVISIÓN TEÓRICA
}

\author{
Marcela Amaya García \\ Mercedes Mardones Corrales ${ }^{* *}$
}

\begin{abstract}
RESUMEN
El presente trabajo de carácter descriptivo se centra en la revisión crítica de los principales aportes relativos al uso de la música como estrategia didáctica para la enseñanza de una segunda lengua, teniendo por objetivos sistematizar el conocimiento disponible en el área, dar cuenta de las diferentes perspectivas con que se aborda e identificar las diferencias entre unas propuestas y otras. Para ello, se emplea como principal estrategia metodológica la investigación documental en tanto técnica de obtención de información (Valles, 1996). El análisis de los planteamientos referidos al objeto de estudio muestra cómo resulta ser un ámbito de la investigación pedagógica que aún no logra tener un referente unívoco.
\end{abstract}

Palabras clave: Música, Didáctica, Enseñanza, Aprendizaje, Segunda Lengua.

\section{MUSIC AS AN INSTRUCTIONAL STRATEGY FOR TEACHING A SECOND LANGUAGE: A THEORETICAL REVIEW}

\begin{abstract}
This descriptive study focuses on the critical review of the main contributions to the use of songs as a learning strategy for teaching a second language. The main aim is to systematize the knowledge available in the area, to account for the different perspectives that are addressed and identify the differences among different proposals. To achieve our goals a documentary research methodology is used as the main strategy to obtain information through the use of technology (Valles, 1996). The analysis of the proposals concerning the object of study shows that this field of educational research does not yet achieve a status of univocal reference.
\end{abstract}

Keywords: Music, Teaching, Teaching Learning, Second Language.

* Doctora (c) en Ciencias de la Educación, Académica Programa Pedagogía en Castellano, Universidad Católica Silva Henríquez, Santiago, Chile. Correo electrónico: mamaya@ ucsh.cl

* Doctora en Metodología de la Enseñanza del Inglés, Edinburgh University, Magíster en Ciencias de la Educación, Universidad de Talca, Santiago, Chile. Correo electrónico: mercedes_983@hotmail.com 


\section{Introducción}

Si bien existe una amplia gama de esfuerzos teóricos relativos al debate del concepto de didáctica y, en particular, sobre el uso de la música y las canciones en la enseñanza de una segunda lengua, lo cierto es que se constata una problemática no menor, esto es, la digresión y falta de sistematización del conocimiento disponible en el área. En consecuencia, con el objetivo de aportar en dicho sentido se plantea el desarrollo de este estudio, que emplea la investigación documental como técnica de recolección de información.

En la primera parte de esta investigación se profundiza en torno al concepto de didáctica y sus principales componentes, entre ellos, el currículum nacional del subsector de inglés. Más adelante, se aborda la pregunta ipor qué incorporar la música en la enseñanza de una segunda lengua?, considerando las respuestas ofrecidas por diversos autores sobre los beneficios de la incorporación de las canciones a la enseñanza de una segunda lengua. Posteriormente, se describen en forma detallada una serie de propuestas aplicativas destinadas a la implementación del uso de la música en el aula, poniendo hincapié en la distinción entre unas y otras. Por último, en las conclusiones se reflexiona sobre los principales hallazgos del estudio, señalando la necesidad de continuar en la profundización de esta cuestión.

\section{Un acercamiento al concepto de didáctica y sus componentes}

Antes de proseguir en la reflexión, se torna necesario dados los fines de este estudio, profundizar sobre qué se ha entendido por didáctica, precisando algunos debates que subyacen al concepto.

Siguiendo a Benedito (1987:II) se tiene que la didáctica es "una ciencia que se construye, desde la teoría y práctica, en ambientes organizados de relación y comunicación intencional, donde se desarrollan procesos de enseñanza y aprendizaje para la formación del alumno". 
Para llegar a la anterior definición, el autor realiza un recorrido por los postulados de diferentes teóricos. Por ejemplo, Titone (I98I) define didáctica como "la ciencia que tiene como objeto específico y formal la dirección del proceso de enseñar hacia fines inmediatos y remotos, de eficacia instructiva y formativa” (Benedito, 1987:12, citando a Titone, I98I).

Stöcker (1964, citado por Benedito, I987:I2), a su vez, entiende el concepto como "la teoría de la instrucción y la enseñanza escolar de toda índole y a todos los niveles”. Por su parte, Mattos (1963) dice que la didáctica es "la disciplina pedagógica de carácter práctico y normativo, que tiene por objeto específico la técnica de la enseñanza; esto es, la técnica de dirigir y orientar eficazmente a los alumnos en su aprendizaje" (Benedito, 1987:13, citando a Mattos, I963).

Finalmente, Fernández Huerta (1964, citado en Benedito, 1987:4) sostiene que la didáctica es una "ciencia que estudia el trabajo docente y discente congruente con los métodos de enseñanza y aprendizaje y que tiene como finalidad la instrucción”.

En tanto, íntimamente relacionado con el concepto de didáctica se encuentra el de estrategia didáctica. Al respecto, Marquès (2000), desde una mirada educativa, señala que este constructo se amplía, entendiéndose como actividades o intervenciones educativas orientadas a mejorar $y$ hacer efectivo cualquier proceso de enseñanza aprendizaje. Según el autor, estas actividades deben ser "(...) motivadoras, significativas, colaborativas, globalizadoras y aplicativas, orientadas a promover los aprendizajes que pretenden contribuir en el desarrollo personal y social de los estudiantes" (Marqués, 2000:s/n).

En este sentido, Marqués (2000:s/n) menciona una serie de procesos a tomar en cuenta en la implementación de estrategias en el ámbito de la educación. A saber:

- Encaminar a los estudiantes hacia el aprendizaje autónomo y promover la utilización autónoma de los conocimientos adquiridos, con lo que aumentará su motivación al descubrir su aplicabilidad. 
- Diseñar entornos de aprendizaje que consideren la utilización (contextualizada e integrada en el currículum) de los medios de comunicación y los nuevos instrumentos informáticos y telemáticos (TIC), aprovechando su valor informativo, comunicativo y motivador. Así preparará oportunidades de aprendizaje para sus alumnos.

- Aprovechar múltiples recursos y las aportaciones didácticas que pueden proporcionar sus distintos códigos y lenguajes.

- Considerar la posibilidad de ofrecer a los estudiantes diversas actividades que puedan conducir al logro de los objetivos (para facilitar el tratamiento de la diversidad mediante diversas alternativas e itinerarios).

En cuanto a las estrategias de aprendizaje, según Fandos y González (2009) es posible identificar varias formas de organizar el trabajo en aula, dependiendo de los fines educativos.

A continuación, se detallan algunas de ellas:

a. Trabajo autónomo: En este caso, es el alumno quien controla todo el proceso, comenzando con la toma de la iniciativa al determinar cuáles son sus metas de aprendizaje, eligiendo el tipo de actividades a realizar, ejecutándolas y finalizando con una etapa de autoevaluación.

b. Trabajo colaborativo o en grupo: La importancia de esta metodología radica en la posibilidad de lograr aprendizajes individuales a través del aporte e intercambio de información, así como tomando decisiones y dando soluciones en conjunto. Sin embargo, para que el trabajo grupal dé resultados positivos debe estructurarse en cuatro ideas pilares que los autores antes referenciados, tomando a Puentes (2002), caracterizan así:

- El primero de los pilares es la comunicación, la cual favorece la interacción en sincronía o asíncrona entre los miembros del grupo.

- La organización, en un segundo momento, pretende favorecer la temporalización y distribución de roles dentro del grupo. 
- Se sucede a continuación la exposición entendida como el intercambio de información y documentación de ideas entre los miembros de un grupo.

- Finalmente, se recoge el conjunto de ideas trabajadas por el grupo después de un proceso de creación, discusión, maduración y concreción (Fandos y González, 2009: s/n).

Por último, resulta importante abordar el concepto de currículum en función de su alcance y cercanía con la didáctica. Según Álvarez (2000), se trata de un constructo casi imposible de definir por su variable polisémica que lo hace adoptar varios significados, relacionándolo con otros conceptos que están dentro de él. Al respecto, señala:

El espacio semántico de currículo ha sido cubierto con palabras como Didáctica, que a su vez abarcan pendularmente los conceptos de enseñanza, aprendizaje, educación, instrucción, programación, plan de estudios, programa, materiales escolares, libros de texto, etc., reflejo sin duda, de la pluralidad semántica que en otras culturas los mismos términos han ocupado. Con ello me refiero al carácter polimorfo (Álvarez, 2000:54).

De acuerdo a la normativa educacional vigente en Chile, el inglés como subsector se encuentra incorporado en el currículum en forma obligatoria a partir de Quinto Básico (NB3), es decir, en el segundo ciclo formativo, fijando un número determinado de horas lectivas semanales. Por cierto, los actuales Programas de Estudio son elaborados por la Unidad de Currículum y Evaluación del Ministerio de Educación (MINEDUC) y datan de 2010. A continuación, se detallan sus principales componentes (MINEDUC, 2010a, 2010b, 2010c, 2010d): 
Tabla I. Programas de Estudio Educación General Básica Ministerio de Educación: Unidades Temáticas

\begin{tabular}{|c|c|c|c|c|}
\hline CURSO & UNIDAD I & UNIDAD II & UNIDAD III & UNIDAD IV \\
\hline 5to Básico & $\begin{array}{c}\text { Our Classroom- } \\
\text { Our School }\end{array}$ & $\begin{array}{c}\text { At Home and } \\
\text { Family }\end{array}$ & Food and Health & $\begin{array}{c}\text { Environment: } \\
\text { Fauna }\end{array}$ \\
\hline 6to Básico & $\begin{array}{c}\text { Myself, my family } \\
\text { and my friends }\end{array}$ & $\begin{array}{c}\text { Hobbies } \\
\text { and sports }\end{array}$ & $\begin{array}{c}\text { Holidays } \\
\text { and celebrations }\end{array}$ & $\begin{array}{c}\text { The city and other } \\
\text { places }\end{array}$ \\
\hline 7mo Básico & Friends & $\begin{array}{c}\text { Sports and sports } \\
\text { events }\end{array}$ & $\begin{array}{c}\text { People: places and } \\
\text { traditions of my } \\
\text { country }\end{array}$ & $\begin{array}{c}\text { Environment and } \\
\text { its care }\end{array}$ \\
\hline 8vo Básico & $\begin{array}{c}\text { Famous people and } \\
\text { places }\end{array}$ & $\begin{array}{c}\text { Addictions and } \\
\text { self-care }\end{array}$ & $\begin{array}{c}\text { Life in other } \\
\text { countries and } \\
\text { communities }\end{array}$ & $\begin{array}{c}\text { Traditions, folklore } \\
\text { and other countries' } \\
\text { literature }\end{array}$ \\
\hline
\end{tabular}

Elaboración propia a partir de MINEDUC, 2010a, 2010b, 2010c, 2010d.

Tabla 2. Programas de Estudio Educación General Básica Ministerio de Educación: Número de Horas por Unidad

\begin{tabular}{|c|c|c|c|c|c|c|}
\hline CURSO & $\begin{array}{c}\text { UNIDAD } \\
\text { I }\end{array}$ & $\begin{array}{c}\text { UNIDAD } \\
\text { II }\end{array}$ & $\begin{array}{c}\text { UNIDAD } \\
\text { III }\end{array}$ & $\begin{array}{c}\text { UNIDAD } \\
\text { IV }\end{array}$ & $\begin{array}{c}\text { TOTAL } \\
\text { HORAS } \\
\text { ANUALES }\end{array}$ & $\begin{array}{c}\% \\
\text { AUMENTO }\end{array}$ \\
\hline 5to Básico & 28 & 28 & 28 & 28 & II 2 & - \\
\hline 6to Básico & 28 & 28 & 28 & 28 & II 2 & $0 \%$ \\
\hline 7mo Básico & 28 & 28 & 28 & 28 & II 2 & $0 \%$ \\
\hline 8vo Básico & 28 & 28 & 28 & 28 & II 2 & $0 \%$ \\
\hline
\end{tabular}

Elaboración propia a partir de MINEDUC, 2010a, 2010b, 2010c, 2010d.

\section{3. ¿Por qué incorporar la música en la enseñanza de una segunda lengua?}

De acuerdo a Arguedas (2009:2), la música en tanto lenguaje del sonido constituye una valiosa herramienta a integrar en los procesos de enseñanza y aprendizaje, pues enriquece la formación de los estudiantes "(...) en los niveles emocional, psicomotor y cognitivo, estimulando el descubrimiento, la experimentación y la creatividad". En efecto, según este autor a través de la música es posible explorar con los estudiantes diversos tipos de lenguajes. 
La educación musical implica un lenguaje verbal, un lenguaje corporal y un lenguaje gráfico o plástico. Así, por ejemplo, al realizar una audición, conviene integrar el lenguaje verbal con una motivación acerca del compositor, el periodo histórico, u otro aspecto que despierte el interés en las personas oyentes (Arguedas, 2009:4).

Para Arguedas (2009: II), entonces, la integración de la música en el proceso de enseñanza-aprendizaje presenta las siguientes ventajas:

(...) Estimula la formación en valores como el respeto mutuo, la diversidad de opiniones y criterios, la disciplina, la socialización, el desarrollo de la autoimagen y la autoestima, el respeto por las reglas que se establecen, la motivación hacia la responsabilidad y la toma de decisiones con libertad, se valora el trabajo de la población estudiantil en forma conjunta y al mismo tiempo de manera individual, lo que permite implementar el trabajo en equipo e impulsar el liderazgo.

Una perspectiva similar presentan Bernal, Epelde, Gallardo y Rodríguez (2010:2), quienes plantean que la colaboración de un especialista del área de la música "(...) facilitaría que el conjunto de aprendizajes se aborden de manera coordinada, y que podamos utilizar la música en el aprendizaje de la lengua y, en este caso, el inglés, para aprender otros contenidos musicales”. Estos mismos investigadores, citando a Bengoechea (2008), realizan las siguientes apreciaciones sobre las canciones y su uso didáctico:

La canción es un instrumento de intercambio, favorece la socialización y además es un contenido significativo en la escuela. Al cantar, y sobre todo al crear canciones, "songwriting", las palabras se interiorizan e incorporan. El valor de las palabras queda enriquecido o internamente incorporado al ir acompañadas de la música y del proceso llevado a cabo para esa integración, que hace de la palabra y la música un fluir continuo desde la expresión a la comunicación (Bernal et al., 2010:2). 
A la vez, Bernal et al. (2010: 2, citando a Bernal y Calvo, 2004) recalcan que en este proceso resulta básico "despertar el placer de escuchar, familiarizándose y reconociendo las características básicas del sonido en cuanto a la altura, la duración, la intensidad y el timbre". Continuando con esta línea argumentativa, los autores antes mencionados enumeran los siguientes beneficios del uso de la música, en general, y las canciones, en particular, en las clases de enseñanza de una segunda lengua.

- Introducir nuevas palabras, ampliando la estructura gramatical.

- Cantar canciones populares inglesas, propia de la cultura del idioma.

- Conocer la historia del País a través de su música (danzas, audiciones, autores).

- Facilitar la entonación fonética del discurso.

- Utilizar estructuras sonoras utilizadas previamente en la clase de música (lenguaje musical).

- Investigar con el sonido para aplicarlo a una estructura gramatical propuesta.

- Enriquecer el vocabulario.

- Realizar experiencias motivadoras (Bernal et al., 2010:3).

Por último, Bernal et al. (2010:5) resumen su postura en relación al aporte de la música como estrategia didáctica para la enseñanza del inglés como sigue:

Consideramos que las canciones son una herramienta indiscutible para desarrollar las capacidades de escucha $y$ expresión, y al unirlas con las palabras o expresiones más frecuentes del idioma inglés podemos conseguir que los alumnos se familiaricen más rápidamente con el idioma facilitando así su enseñanza-aprendizaje.

Sobre este mismo punto, Merino (2008:103) señala que la canción es un material de enorme originalidad y aprovechable en la enseñanza de diversos idiomas, debido a su potencial motivador y amplitud de 
posibilidades didácticas, “(...) lo que permite la implementación de diversas actividades que ayudan al docente a llevar al alumnado al descubrimiento de información y al refuerzo de estructuras vistas en clase". A la vez, esta autora asevera que "las canciones sí constituyen un medio efectivo para la práctica y aprendizaje de la lengua inglesa, así como para la aproximación a su cultura y su interrelación con el área de Educación Musical” (Merino, 2008:108), agregando que el uso de la música en la clase de enseñanza de una segunda lengua es un aporte para la toma de conciencia de los estudiantes respecto de la importancia de este idioma.

Nos ayuda a hacer ver a nuestros alumnos y alumnas que la lengua inglesa no es meramente un área del currículo que deben aprobar, sino que es algo que está a nuestro alrededor, que forma parte de nuestra vida cotidiana y que merece la pena ser estudiada y adquirida (Merino, 2008:108).

Medina y Dzay (2007), al igual que Merino en relación al uso de la música en la enseñanza de una segunda lengua, ponen énfasis en el potencial de contexto que ésta posee. Para ello, Medina y Dzay (2007:225, partiendo de Rogers y Medley, 1988) comentan que constituye un "material auténtico como ejemplos de lenguaje, ya sea oral o escrito, que refleja una naturaleza de forma y una propiedad de contexto cultural y situacional que podría ser encontrado en el lenguaje como es usado por un hablante nativo".

Al mismo tiempo, Medina y Dzay (2007:225) con el objetivo de reforzar la idea anterior, citando a Geddes y White (1978), indican que éstos "recomiendan el uso del material auténtico tanto como sea posible en la enseñanza [, pues] este movimiento hacia la autenticidad en la enseñanza del lenguaje refleja un incremento en interés hacia las funciones comunicativas en los últimos años”.

Ahora bien, los investigadores antes referenciados explican las razones por las cuales utilizar materiales auténticos en el salón de clases. Así, parafraseando a Gower, Phillips y Walter (I995), entregan el siguiente listado: 
a. Son 'reales', intrínsecamente más interesantes y motivantes, y dan a los alumnos mucha confianza respecto al idioma cuando son capaces de entender lo que en el material se expresa.

b. Proporcionan ejemplos tal y como son encontrados en la vida real. Al ser expuestos al material auténtico de audio, los alumnos tienen la oportunidad de adquirir o "agarrar" la lengua. c. El contenido cultural de muchos materiales auténticos estimula a los alumnos a involucrarse más con el idioma.

d. El uso de material auténtico puede ser ligado a las diferentes maneras de ayudar a los alumnos a ser más independientes en su aprendizaje: haciendo predicciones, usando libros de referencia (libros de gramática, vocabulario, diccionarios) (Medina y Dzay, 2007:226, citando a Gower, Phillips y Walter, I995).

Según Medina y Dzay (2007:235) el principal impacto del uso de material auténtico, en este caso, canciones, es que ayuda a los alumnos "al aumento en su comprensión, además de proporcionarles las herramientas necesarias, basadas en el uso de las estrategias enfocadas al audio, desarrolladas durante el curso-taller".

Valdez (s/f: 332), en un sentido equiparable, señala que las canciones poseen importantes potencialidades en el ámbito didáctico, "(...) pues éstas son una de las formas de incrementar vocabulario, lenguaje coloquial y contracciones del habla. Además de practicar pronunciación y comprensión auditiva, por lo que facilitan el aprendizaje”. Gutiérrez y Beltrán (1995:67) añaden que "el beneficio indudable de aprender las canciones elaboradas al efecto habría que estimular la capacidad de invención de sencillas recitaciones rítmicas por parte del propio profesor y de los alumnos. No tiene por qué ser difícil”.

Ruiz (2008) y Ramírez (2009), en tanto, relevan una serie de razones por las cuales incorporar la música y las canciones como estrategias didácticas. En primer lugar, Ruiz (2008) considera razones de tipo afectivo, cognitivo y lingüístico; mientras Ramírez (2009) da lugar a consideraciones de índole psicológica, pedagógica y metodológica. 
Molina (2009:3) coincide con los autores antes comentados, diciendo que "para la mayoría de los y las estudiantes, escuchar música es un placer, tanto que, con frecuencia, llegan a insistirle al profesor o profesora para que desarrolle esta actividad en el aula una y otra vez". Según la investigadora esto se debe a que "este proceso hace que aumente el nivel de confianza del alumnado, que pongan sus temores sobre posibles errores en un segundo plano y se dediquen por completo a la motivadora actividad de aprender canciones en la segunda lengua" (Molina, 2009:3).

Leal (1998:100), por su parte, realiza una reflexión y, quizás, un llamado al profesorado en relación a la apertura de sus aulas a este tipo de estrategias, señalando:

Nuestros alumnos conocen el ritmo de la canción, y muchas veces incluso la tararean pero no lo hacen correctamente por la sencilla razón de que desconocen la letra de la misma. (...) Es decir vemos en nuestros alumnos (en los adolescentes, en general) una tendencia y una inclinación natural hacia la canción. Inclinación que podría aumentar si vieran una actitud positiva por nuestra parte hacia la música moderna. (...) Debemos procurar que el uso de la canción en la clase sea una actividad creativa y sobre todo divertida: que el alumno se divierta mientras aprenda.

En este contexto, el autor considera que "la gran ventaja de la canción radica en el hecho de que puede ser recordada con gran facilidad, sin duda, mucho más que un poema y muchísimo más que cualquier otro texto" (Leal, I998:100). No obstante, Palomares, Madrid, Muros y Pardo (1990:129) señalan que resulta crucial que los docentes de una segunda lengua incorporen en sus clases el uso de música, considerando siempre el nivel de inglés de los estudiantes.

A modo de resumen de lo expuesto en este apartado, se presenta el aporte realizado por Fandiño y Viaplana (2008:I77-I78, citando a Martínez Sallés, 2002). 
En primer lugar, el trabajo con canciones es recibido siempre por parte de los aprendientes como una actividad motivadora. En clase, como en la vida, las canciones ayudan a la diversión, a la relajación y a la creación de un buen ambiente. En segundo lugar, aunque las canciones son materiales reales, auténticos, creados en la LO para ser recibidos en la LO, son también fácilmente reconocibles e interpretables por los estudiantes de L2, gracias a su carácter de producto intercultural. Por lo demás, es sabido que la música, aparte de amansar a las fieras, tiene la capacidad de estimular en nuestro cerebro zonas relacionadas con las emociones, y en este sentido puede resultar un 'recurso facilitador para abrir el filtro afectivo y permitir la entrada de input'.

\section{Propuestas aplicativas}

A continuación, se presenta una revisión teórica de diferentes propuestas sobre cómo trabajar con música y canciones en la enseñanza de una segunda lengua.

Según Molina (2009), son muchas las actividades que se pueden llevar a cabo usando canciones; entre ellas, se cuentan: rellenar huecos, ordenar estrofas y versos, buscar sinónimos y antónimos, unir con flechas, seleccionar la respuesta adecuada y elegir la palabra correcta, buscar palabras que se correspondan con ciertos sonidos, diferenciar el lenguaje formal del informal y contar las veces que se repiten determinadas palabras. Molina (2009:3) recalca que a través de este tipo de instancias se puede conseguir:

- Perfeccionar la pronunciación de los alumnos y alumnas.

- Aumentar el vocabulario activo y pasivo.

- Desarrollar la comprensión lectora del lenguaje poético.

- Introducir la historia y cultura anglo-americana a través del tema de las canciones.

- Educar en valores.

- Incrementar el interés por las clases de inglés y enseñar y divertir al mismo tiempo. 
Chacón (2009:I), también, valora el aporte de la música como material de apoyo en las claves, puesto que ésta "en las pocas líneas de que se compone su letra se encuentran una gran cantidad de estructuras gramaticales y actos de habla que pueden ser estudiados y analizados por el profesor y aprendidos casi inconscientemente por parte de los alumnos (...)”. En este contexto, para esta autora las canciones, en especial, el pop y el folk -que según ella reflejan las tendencias modernas y suelen ser de interés de los jóvenes- pueden ser usadas para: "Introducir nuevas estructuras en contextos con significado; reforzar las estructuras que los estudiantes ya saben; aumentar el vocabulario $(y)$ repasar el vocabulario que ya se sabe" (Chacón, 2009:2).

Ramírez (2009), a su vez, profundiza su aporte sobre la temática, vinculando el uso de las canciones como creaciones literarias y diferenciando el tipo de canciones, según ciclo educativo. En primer lugar, la autora agrupa en torno a la literatura una serie de textos orales, entre ellas, las rimas, canciones tradicionales, las adivinanzas, dichos y trabalenguas con las cuales es posible trabajar la creatividad desde diversos ángulos. A saber:

- Implican movimientos, gestos, actuación.

- Se pueden crear materiales adicionales con las canciones (máscaras, vestidos, marionetas recortables).

- Imitar personajes reales o imaginarios.

- Pueden ser interpretadas.

- Pueden ser usadas para desarrollar creatividad por medio de sus letras.

- Mejoran la imaginación por medio de comparaciones y contrastes con la realidad.

En segundo lugar, Ramírez (2009) sostiene que existen tres tipos de canciones, esto es, de acción (por ejemplo, "The Hokey Pokey"), tradicionales (por ejemplo, "Merry Christmas") y pop, cuya selección debe tomar en cuenta criterios tales como: evitar canciones con pausas musicales largas, y la edad de los estudiantes y sus intereses. En función de esto, la autora propone usar canciones de acción y 
tradicionales en el primer y segundo ciclo de Educación Primaria, pues "los niños se divierten cantando en voz alta y su sentido del ridículo no está desarrollado, mueven sus cuerpos sintiendo la música” (Ramírez, 2009:4). Para el tercer ciclo de Educación Primaria, Ramírez (2009:6) plantea el uso de canciones pop como las de High School Musical, Hannab Montana y Jonas Brothers, ya que "en esta etapa empiezan a escuchar música en la radio y debemos tomar ventaja de sus nuevos intereses, intentando encontrar canciones que les gusten, y a la vez, adecuadas a nuestros propósitos”.

Por último, la autora referenciada señala que las canciones se pueden emplear para fomentar la pronunciación al trabajar con ellas las características segmentales y suprasegmentales de la lengua; aumentar el vocabulario; fomentar el debate y la discusión, así como situar a los estudiantes en la cultura de dichas canciones. No obstante, Ramírez (2009) precisa que el profesorado debe maximizar el uso de las canciones, acompañándolas de estrategias de enseñanza, tales como:

- Antes de presentar la canción, retaremos a los alumnos a averiguar el vocabulario objeto de estudio, el tema de la canción.

- Antes de hacer las actividades, pedir a las parejas o pequeños grupos que intercambien ideas y discutan sobre sus diferentes puntos de vista y opiniones.

- Fomentar el canto en coro.

- Evitar poner canciones para rellenar el tiempo.

- Usar grabaciones en buen estado.

- Poner el reproductor de CD antes de clase para evitar posibles fallos.

- Conocer el punto exacto donde comienza la canción.

Una propuesta, también, detallada es la de Ruiz (2008), quien delimita claramente los criterios para seleccionar la música a usar en la clase de una segunda lengua: la edad del alumnado, nivel de vocabulario, estructuras y funciones, empleo de canciones auténticas o adaptadas y los intereses y la motivación del alumno. A su vez, para esta autora resulta clave determinar qué tipo de canciones se 
incorporarán al trabajo en aula, pudiendo los docentes elegir -según el fin pedagógico- entre couting song, action song, tradicional songs, rounds, nursery rimes, jazz chants, song for special occasion, folk songs.

Ahora bien, la autora ofrece una depurada metodología para enseñar a través de canciones, que considera los pasos siguientes: contextualizar a los estudiantes, mostrándoles dibujos apropiados; escuchar la canción y observar las acciones que realiza el profesor o cantar y realizar las acciones al mismo tiempo y repetir la canción como actividad final. Asociado a lo anterior, Ruiz (2008) divide las actividades a realizar en el aula, estableciendo tres categorías: pre-song activities, es decir, acciones anteriores a la escucha activa de la canción (juegos con tarjetas para presentar el vocabulario); while-song activities, entendidas como actividades a efectuarse durante el desarrollo de la canción (action songs) y, post-listening to music activities, usadas para reforzar los contenidos (play time and post son activities, mime, sequencing, which frame, etc.).

Por su parte, Palomares et al. (1990) realizan una propuesta didáctica a partir de una lista de 40 canciones tradicionales por medio de las cuales el docente puede abarcar con el estudiantado el análisis lingüístico en sus dimensiones fonética, morfosintáctica y semántica, el desarrollo de las destrezas comunicativas, profundizar en los comentarios de los rasgos estilísticos y socioculturales y fomentar las actividades musicales. Como se observa, la perspectiva de estos autores resulta ser bastante integradora al considerar elementos no previstos por los investigadores revisados con anterioridad. Al respecto, aseveran que "el esquema didáctico que hemos propuesto favorece una explotación sistemática y permite el análisis de todos los elementos básicos de los textos" (Palomares et al., I990:130).

Merino (2008), siguiendo con esta perspectiva, plantea cinco ámbitos a tratar con la música en la enseñanza de idiomas: aspecto histórico, sociológico y cultural, aspecto psicológico y comparativo, aspecto rítmico y prosódico, léxico y aspecto lingüístico. Así, para abordar estas dimensiones la autora entrega algunos ejemplos de actividades, tomando como base una canción, distinguiéndose la escritura de otra 
letra para la misma melodía (rewriting the lyrics); el estudio centrado en una estructura determinada (focus on), estribillos estructurales (sung drills); las dramatizaciones de las canciones (sung dramatizations), resumen de la canción (summary of the song); el trabajo creativo (creative work); los versos desordenados (jumbled lines) y la reconstrucción de la canción (reconstruction of the song). Cabe señalar que las tareas diseñadas por esta autora apuntan al fomento de diversos procesos cognitivos y habilidades procedimentales.

Leal (1998), por otra parte, centra su aporte en el uso de un tipo específico de canción en el aula, esto es, la llamada canción comprometida que se caracteriza por tener mayor cantidad de texto, el estribillo se repite con menor frecuencia y presenta estructuras gramaticales de mayor complejidad, debido a las temáticas tratadas. De este modo, el autor considera dos maneras de explotar las canciones desde este enfoque:

a. Contraste: Implica contrastar dos o más canciones de elevada carga semántica. En este punto Leal (1998) considera como cruciales las actividades destinadas a abordar temas como el abismo generacional; la falta de solidaridad con el desarraigado; la educación; la guerra; la existencia de un mundo mejor, la aniquilación de los indios y la nostalgia del tiempo que pasa. Para llevar a cabo esto, el autor presenta una lista compuesta por más de 40 canciones, entre ellas, "Belfast", "El Lute" y "I9".

b. Trabajar sobre el texto de la canción. En este caso, el autor plantea observar temas, tales como: el mundo que desaparece, la guerra fría, los desaparecidos en combate, las ansias de revolución, la búsqueda de la libertad, la Dictadura y el cambio político.

De acuerdo a Leal (1998), usar la canción comprometida en la enseñanza del inglés tiene por objetivo que los estudiantes se aproximen a las problemáticas del mundo desarrolladas en las letras a medida que aprenden un segundo idioma.

Fandiño y Viaplana (1998) rebasan la mera cuestión práctica, 
tomando como base teórica el enfoque comunicativo por tareas, donde cada actividad de la secuencia tiene por objetivo final el logro de la tarea. De esta manera, establecen tres momentos de la secuencia didáctica: la fase inicial (preaudición) en que se contextualiza la actividad mediante imágenes, hipótesis o inferencias; la fase de desarrollo (audición), donde se efectúan actividades relacionadas con ilustración del texto, correlación de información, respuesta de preguntas abiertas y cerradas, y la fase de postaudición en que se releva la producción escrita.

Un aporte orientado de forma similar es el de Medina y Dzay (2007), quienes recogen de Nunan (1995) y Richards (I983) una serie de estrategias para comprensión auditiva. En relación a lo expuesto por Nunan (1995), Medina y Dzay (2007:227) comentan que "para desarrollar la habilidad de la comprensión auditiva se puede utilizar una gran variedad de ejercicios (...) que van desde la simple discriminación de fonemas o palabras, hasta la comprensión global de fragmentos de lenguaje oral” y, en cuanto a Richards (I983), dicen que éste propone un modelo del proceso de comprensión auditiva que consta de los siguientes pasos:

- Se determina el tipo de evento en el material (una conferencia, un discurso, una conversación, un debate, etc.).

- Los esquemas o guiones relevantes de una situación particular son recuperados por la memoria a largo plazo.

- El o los objetivos de los hablantes son inferidos tanto a través de las referencias del contexto como de los guiones.

- Un significado literal es determinado por el estilo.

- Se asigna un significado deliberado al mensaje.

- Finalmente, se retiene esta información y la forma del mensaje original es borrada para dar lugar al mensaje nuevo y real (Medina y Dzay, 2007:228, citando a Richards, 1983).

Profundizando la propuesta de Richards (I983), Medina y Dzay (2007) añaden que el autor considera el desarrollo de 33 micro-habilidades necesarias para la comprensión auditiva y otras 
I8 utilizadas en las escuelas, destacándose habilidades como la discriminación de sonidos; el reconocimiento de patrones sintácticos e identificación de palabras claves, la extracción de ideas principales, etc. Finalmente, los investigadores precisan que Richards (1983) enumera una serie de actividades en relación a los niveles de destreza de los estudiantes, dando lugar a la tabla 3 :

Tabla 3: Actividades de acuerdo a tipo de destreza de los estudiantes

\begin{tabular}{|c|c|c|}
\hline NIVEL & $\begin{array}{l}\text { PRINCIPIANTE/ } \\
\text { INTERMEDIO }\end{array}$ & AVANZADO/SUPERIOR \\
\hline \multirow{12}{*}{$\begin{array}{c}\text { TIPO DE } \\
\text { ACTIVIDADES }\end{array}$} & $\begin{array}{l}\text { Actividades previas a la } \\
\text { comprensión auditiva. }\end{array}$ & Resumir. \\
\hline & $\begin{array}{l}\text { Escuchar para tener una idea } \\
\text { general del texto. }\end{array}$ & Tomar notas. \\
\hline & $\begin{array}{l}\text { Escuchar con la ayuda de } \\
\text { imágenes. }\end{array}$ & $\begin{array}{l}\text { Inferir (en un nivel en el que } \\
\text { los alumnos tienen que sacar } \\
\text { conclusiones no presentadas en } \\
\text { el texto). }\end{array}$ \\
\hline & $\begin{array}{l}\text { Unir descripciones con } \\
\text { dibujos. }\end{array}$ & $\begin{array}{l}\text { Identificar factores } \\
\text { sociolingüísticos. }\end{array}$ \\
\hline & Dictar. & $\begin{array}{c}\text { Actividades de reacción y } \\
\text { análisis. }\end{array}$ \\
\hline & Escuchar palabras clave. & $\begin{array}{c}\text { Actividades de elaboración } \\
\text { creativa. }\end{array}$ \\
\hline & $\begin{array}{l}\text { Escuchar para distinguir } \\
\text { registros (formales, } \\
\text { informales, estilo). }\end{array}$ & \\
\hline & Inferir información. & \\
\hline & Parafrasear. & \\
\hline & Llenar espacios vacíos. & \\
\hline & Ordenar oraciones. & \\
\hline & Opción múltiple. & \\
\hline
\end{tabular}

Elaboración propia a partir de Medina y Dzay (2007).

Otro aporte en esta revisión es el de Valdez (s/f), quien entiende las canciones como cuna del aprendizaje de una lengua. Haciendo suya dicha premisa, la autora sostiene que éstas se pueden incorporar al aula bajo diversos rótulos, entre ellos, la canción y la poesía; las canciones populares; el lenguaje como asociación; la cultura y la 
canción; las canciones y música como complementos destinadas al análisis de textos; para la comunicación efectiva; la enseñanza del vocabulario; la práctica de pronunciación y el desarrollo de la memoria. Asimismo, Valdez (s/f) refuerza lo expuesto por medio de los resultados de un estudio referido al uso didáctico de las canciones en la enseñanza de una segunda lengua:

a. El $64,9 \%$ de los estudiantes considera que el empleo de canciones en el aprendizaje es un buen método.

b. El $24,4 \%$ de los estudiantes piensa que el uso de canciones en el aprendizaje es un excelente método.

c. El $60 \%$ de los profesores declara que usa rara veces las canciones en el aula.

d. El 80\% de los profesores asegura que las canciones sí son de utilidad en el aprendizaje del idioma.

e. Los principales beneficios de las canciones en la enseñanza de una segunda lengua son incremento de vocabulario y pronunciación, con un $28,5 \%$.

Por último, a modo de síntesis de las reflexiones presentadas a lo largo de este apartado se presenta la siguiente tabla:

\section{Tabla 4: SÍNTESIS PROPUESTAS APLICATIVAS}

\begin{tabular}{|l|l|l|}
\hline AUTOR & ACTIVIDADES A REALIZAR & \multicolumn{1}{|c|}{ APORTE } \\
\hline $\begin{array}{l}\text { MOLINA } \\
(\mathbf{2 0 0 9 )}\end{array}$ & $\begin{array}{l}\text { Buscar sinónimos y antónimos } \\
\text { y palabras que se correspondan } \\
\text { con ciertos sonidos, etc. }\end{array}$ & $\begin{array}{l}\text { Se centra en la enseñanza del } \\
\text { nivel léxico y fonológico de la } \\
\text { lengua. }\end{array}$ \\
\hline $\begin{array}{l}\text { CHACÓN } \\
(\mathbf{2 0 0 9 )}\end{array}$ & $\begin{array}{l}\text { Analizar estructuras } \\
\text { gramaticales y actos de habla. }\end{array}$ & $\begin{array}{l}\text { El eje está en el aprendizaje de } \\
\text { las estructuras gramaticales en } \\
\text { contextos. }\end{array}$ \\
\hline $\begin{array}{l}\text { RAMÍREZ } \\
(\mathbf{2 0 0 9 )}\end{array}$ & $\begin{array}{l}\text { Crear máscaras, vestidos, } \\
\text { marionetas recortables; } \\
\text { imitar personajes reales o } \\
\text { imaginarios, etc. }\end{array}$ & $\begin{array}{l}\text { Vincula las canciones } \\
\text { con creaciones literarias y } \\
\text { diferencia el tipo de canciones } \\
\text { a emplear. }\end{array}$ \\
\hline RUIZ (2008) & $\begin{array}{l}\text { Desarrollar pre-song activities, } \\
\text { while-song activities, y, post-listening } \\
\text { to music activities. }\end{array}$ & $\begin{array}{l}\text { Describe una metodología } \\
\text { para la incorporación de la } \\
\text { música al aula. }\end{array}$ \\
\hline $\begin{array}{l}\text { PALOMARES } \\
\text { ET AL. (1990) }\end{array}$ & $\begin{array}{l}\text { Efectuar análisis lingüístico, } \\
\text { desarrollar destrezas } \\
\text { comunicativas, etc. }\end{array}$ & $\begin{array}{l}\text { Permite el análisis de todos } \\
\text { los elementos básicos de los } \\
\text { textos. }\end{array}$ \\
\hline
\end{tabular}


La música como estrategia didáctica para la enseñanza de una segunda lengua: una revisión teórica - Marcela Amaya García y Mercedes Mardones Corrales

\begin{tabular}{|l|l|l|}
\hline $\begin{array}{l}\text { MERINO } \\
(\mathbf{2 0 0 8 )}\end{array}$ & $\begin{array}{l}\text { Desarrollar la escritura de } \\
\text { otra letra para la misma } \\
\text { melodía; el estudio centrado } \\
\text { en una estructura determinada } \\
\text { y dramatizaciones de las } \\
\text { canciones, etc. }\end{array}$ & $\begin{array}{l}\text { Fomenta el trabajo de aspectos } \\
\text { sociológicos, psicológicos y } \\
\text { lingüísticos. }\end{array}$ \\
\hline LEAL (I998) & $\begin{array}{l}\text { Efectuar actividades de } \\
\text { contraste y trabajar sobre el } \\
\text { texto de la canción. }\end{array}$ & $\begin{array}{l}\text { Propone el uso en el aula de } \\
\text { la canción comprometida para } \\
\text { acercar a los estudiantes a las } \\
\text { problemáticas del mundo real. }\end{array}$ \\
\hline $\begin{array}{l}\text { FANDIÑO Y } \\
\text { VIAPLANA } \\
\text { (I998) }\end{array}$ & $\begin{array}{l}\text { En la fase inicial, potenciar } \\
\text { las inferencias; en la fase de } \\
\text { desarrollo, plantear actividades } \\
\text { relacionadas con ilustración } \\
\text { del texto, entre otras y la fase } \\
\text { de postaudición, relevar la } \\
\text { producción escrita. }\end{array}$ & $\begin{array}{l}\text { Se basa en el enfoque } \\
\text { comunicativo por tareas y } \\
\text { asocia a la secuencia didáctica } \\
\text { determinados tipos de } \\
\text { actividades. }\end{array}$ \\
\hline $\begin{array}{l}\text { MEDINA Y } \\
\text { DZAY (2007) }\end{array}$ & $\begin{array}{l}\text { Discriminar fonemas o } \\
\text { palabras y fomentar la } \\
\text { comprensión global de } \\
\text { fragmentos de lenguaje oral. }\end{array}$ & $\begin{array}{l}\text { Se centra en estrategias para } \\
\text { comprensión auditiva. }\end{array}$ \\
\hline VALDEZ (S/F) & $\begin{array}{l}\text { Efectuar análisis de textos, } \\
\text { potenciar la comunicación } \\
\text { efectiva, etc. }\end{array}$ & $\begin{array}{l}\text { Incorporación de la música al } \\
\text { aula bajo diversos rótulos. }\end{array}$ \\
\hline
\end{tabular}

Elaboración propia.

\section{Conclusiones}

A partir de la revisión teórica desarrollada a lo largo de este estudio se tiene lo siguiente:

I. La música es considerada, en general, como un recurso didáctico útil en las clases de una segunda lengua, dado su carácter motivador hacia los estudiantes.

2. Los autores esgrimen diversas razones para considerar la música y las canciones como estrategia didáctica para la enseñanza de una segunda lengua, de este modo, no existe entre la comunidad académica consenso sobre este tópico.

3. Una situación similar a la antes descrita se corrobora en relación a los beneficios que implica incorporar la música al aula con fines didácticos. Por ahora, lo claro es que todos los autores coinciden 
en la necesidad de que los profesores abran sus espacios de aula hacia este tipo de innovaciones, debido al mejoramiento de los procesos educativos que experimentan los estudiantes.

4. En términos prácticos, las propuestas aplicativas sobre el uso de la música y las canciones para la enseñanza de una segunda lengua dan cuentan de criterios disímiles en su construcción. No obstante, en general, los teóricos concuerdan en elementos como la necesidad de asociar el tipo de actividades a desarrollar con los estudiantes con las destrezas de éstos, cautelando así el logro efectivo de los aprendizajes.

5. Las propuestas aplicativas tienden a incorporar entre las dimensiones a trabajar aspectos ya sean lingüísticos como socioculturales. De este modo, los investigadores pretenden optimizar el uso de la música como recurso didáctico, explotando sus diferentes potencialidades.

6. La dificultad para establecer criterios unívocos en relación a la temática abordada en este estudio se condice con los debates existentes respecto al campo de la didáctica, por lo tanto, constituye un área de los estudios pedagógicos en la que se debe seguir profundizando en función de las emergencias de las propias prácticas de aula de los docentes.

\section{Bibliografía}

Álvarez, J. (2000). Didáctica, currículo y evaluación: Ensayos sobre las cuestiones didácticas. Buenos Aires: Miño y Dávila Editores.

Arguedas, C. (2009). Música y expresión corporal en los procesos de enseñanza y aprendizaje del inglés, español y francés. Actualidades Investigativas en Educación, 9, I-3I.

Benedito, V. (1987). Introducción a la didáctica: Fundamentación, teoría y diseño curricular. Barcelona: Barcanova.

Bernal, J.; Epelde, A.; Gallardo, M. y Rodríguez, A. (2010). La música en la enseñanza-aprendizaje del inglés. Ponencia presentada en el II Congrés Internacional de Didáctiques, Girona, España.

Chacón, M. (2009). Beneficio del juego y la canción en el aula de inglés. Innovación y Experiencias Educativas, I6, I-I3. 
La música como estrategia didáctica para la enseñanza de una segunda lengua: una revisión teórica - Marcela Amaya García y Mercedes Mardones Corrales

Fandiño, Z. y Viaplana, A. (2008). Canciones en la clase de ELE. Ponencia presentada en las Jornadas de Formación del Profesorado en la Enseñanza de ELE y la Literatura Española Contemporánea, Sofía, Bulgaria.

Fandos, M. y González, A (2009). Estrategias de aprendizaje ante las nuevas posibilidades educativas de las TIC. Disponible en: http://www.formatex.org/ micte2005/227.pdf

Gutiérrez, G. y Beltrán, F. (I995). La enseñanza de idiomas como acción cultural. Encuentro, 8, 60-70.

Leal, P. (1998). La canción comprometida en el aula de inglés. Encuentro. Revista de Investigación e Innovación en la Clase de Idiomas, I0, 99-I08.

Marquès, P. (2000). Los docentes: funciones, roles, competencias necesarias, formación. Disponible en: http://formacioncontinuaedo mex.files.wordpress. com/20II/06/ peremarques-los-formadores-ante-la-sociedad.pdf

Medina, S. y Dzay, F. (2007). Material auténtico de audio en la enseñanza del inglés. Ponencia presentada en III Foro Nacional de Estudios en Lenguas (FONAEL 2007), Quintana Roo, México.

Merino, M. (2008). El uso de la música en la clase de inglés. Revista Digital Enfoques Educativos, 21, 103-109.

MINEDUC (2010a). Programa de estudio inglés quinto básico. Santiago: MINEDUC. (2010b). Programa de estudio inglés sexto básico. Santiago: MINEDUC. (20I0c). Programa de estudio inglés séptimo básico. Santiago: MINEDUC. (2010d). Programa de estudio inglés octavo básico. Santiago: MINEDUC.

Molina, M. (2009). La música en la clase de inglés. Innovación y Experiencias Educativas, 25, I-9.

Palomares, J.; Madrid, D.; Muros, J. y Pardo, M. (1990). Posibilidades didácticas de las canciones en la clase de inglés. Ponencia presentada en las $\mathrm{V}$ Jornadas Pedagógicas para la Enseñanza del Inglés, Granada, España.

Ramírez, R. (2009). La canción en el área de inglés. Innovación y Experiencias Educativas, 25, I-II.

Ruiz, M. (2008). La enseñanza de idiomas a través de la música. Innovación y Experiencias Educativas, I3, I-IO.

Valdez, S. (s/f). Las canciones en el aprendizaje de lenguas. Disponible en: http://fel. uqroo.mx/adminfile/files/memorias/Articulos_Mem_FONAEL_I/ Valdez_Sandra.pdf

Valles, M. (1996). Técnicas cualitativas de investigación social. Reflexión metodológica y práctica profesional. Madrid: Editorial Síntesis. 